\title{
Thoracoscopic resection of a bronchogenic cyst in a 17-year-old girl
}

\author{
Roksana Puttorak, Wojciech Korlacki, Michał Pasierbek, Andrzej Grabowski \\ Department of Children's Developmental Defects Surgery and Traumatology, School of Medicine with \\ the Division of Dentistry in Zabrze, Medical University of Silesia in Katowice, Poland
}

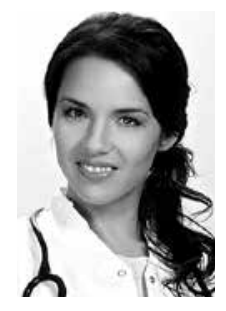

Kardiochirurgia i Torakochirurgia Polska 2016; 13 (4): 370-372

\begin{abstract}
Bronchogenic cysts comprise approximately $6 \%$ of mediastinal tumors in children. The treatment consists in surgical resection of the cyst. The authors present the case of a 17-year-old girl who was accidentally diagnosed with a mediastinal cyst. The patient was successfully treated with thoracoscopic surgery with good early and late clinical outcomes.

Key words: bronchogenic cyst, mediastinal mass, thoracoscopy, child.
\end{abstract}

\section{Introduction}

Bronchogenic cysts account for approximately $6 \%$ of mediastinal tumors found in children [1]. They are thought to originate from abnormal embryogenesis between the $4^{\text {th }}$ and $8^{\text {th }}$ week of gestation [2]. Bronchogenic cysts can cause symptoms such as persistent cough, hoarseness, recurrent pneumonia, and - in the case of large tumors pressing on the adjacent organs of the mediastinum - dyspnea, acute respiratory failure, difficulty in swallowing, superior vena cava syndrome, and Horner's syndrome. If the cyst remains asymptomatic, it can be discovered as an incidental finding $[1,3,4]$. The recommended management method is surgical excision [1, 5-8].

We report the case of a 17-year-old female patient who underwent successful thoracoscopic excision of a bronchogenic cyst; the report is followed by a review of the literature.

\section{Case report}

The 17-year-old female patient was admitted in order to undergo the removal of a cystic tumor of the upper mediastinum. The patient was diagnosed at the age of 10 while being examined after a chest trauma. Postero-anterior chest X-ray revealed a widened shadow on the left side of the upper mediastinum within the aortic arch.

A computed tomography (CT) scan confirmed the presence of a cystic mass within the left upper mediastinum, situated laterally from the arch of the aorta and the pulmo-

\section{Streszczenie}

Torbiele oskrzelopochodne stanowią ok. 6\% guzów śródpiersia u dzieci. Leczenie polega na chirurgicznej resekcji torbieli. Autorzy przedstawiają przypadek 17-letniej dziewczynki, u której przypadkowo zdiagnozowano torbiel śródpiersia. Pacjentka została poddana udanemu leczeniu za pomocą chirurgii torakoskopowej z dobrymi wczesnymi i odległymi wynikami klinicznymi. Słowa kluczowe: torbiel oskrzelopochodna, guz śródpiersia, torakoskopia, dziecko.

nary trunk (Fig. 1). The mass was defined as a well-circumscribed, thin-walled area filled with dense, homogeneous, hypodense liquid. There was no mediastinal adenopathy or communication between the cyst and the adjacent structures. At the same time, the CT scan revealed a parenchymal triangular area corresponding to persistent thymus.

Since the diagnosis, the patient has remained under constant ambulatory control. In subsequent chest CT scans, the cyst remained stationary - no significant changes were observed in its size or characteristics. The dimensions of the cyst in magnetic resonance imaging (MRI) of the chest were comparable with those described after previous examinations (CC $5.2 \mathrm{~cm} \times \mathrm{SD} 4.1 \mathrm{~cm} \times$ AP $4.2 \mathrm{~cm}$ ). Magnetic resonance imaging also showed modeling of the left lung and aortic arch by the lesion; the image of persistent thymus was stationary. No other pathological changes in the mediastinum were found. Due to emerging symptoms in the form of hoarseness and dry cough, a decision was made to perform surgery. The resection was performed using a thoracoscopic procedure. After the induction of general anesthesia, the patient was intubated with a standard endotracheal tube. Intubation with a double-lumen endotracheal tube was abandoned, and the deflation of the left lung was obtained with pleural insufflation pressure of about $8 \mathrm{~mm} \mathrm{Hg}$. Three ports were placed: one $10 \mathrm{~mm}$ trocar in the anterior axillary line in the fourth intercostal space and two $5 \mathrm{~mm}$ trocars in the third intercostal space - the first in the midaxillary line and the second near the mammary line.

Address for correspondence: Wojciech Korlacki, Department of Children's Developmental Defects Surgery and Traumatology, Medical University of Silesia, ul. 3 Maja 13-15, 41-800 Zabrze, Poland, phone: +48 605733 991, fax: +48 3237043 54, e-mail: woko@plusnet.pl

Received: 11.03.2016, accepted: 5.08.2016. 
Intraoperatively, the cyst was found to be overlying the root of the left lung, the left pulmonary artery, and the descending aorta; it was adjacent anteriorly to the left atrium and the ascending aorta (Fig. 2). A harmonic scalpel was used to separate the cyst from the surrounding tissues; special attention was paid to dissecting the anterior part of the cyst from the phrenic nerve and the posterolateral part from the vagus and recurrent laryngeal nerves (Fig. 3).

The cyst was dissected free from the trachea and the left pulmonary artery; it was then removed by sucking the mucous content through the aperture in the $10 \mathrm{~mm}$ trocar. The operative field was rinsed with an antibiotic solution, and a drain was placed. The surgery lasted $90 \mathrm{~min}$. The chest drain was removed from the pleural cavity on the $1^{\text {st }}$ postoperative day after a chest $X$-ray inspection confirmed the overall expansion of the left lung. To confirm the completeness of the surgery, a CT scan of the chest was performed on the $2^{\text {nd }}$ postoperative day, revealing no embedded fluid reservoirs within the mediastinum. The patient was discharged on the $3^{\text {rd }}$ postoperative day in good general condition.

The patient had no complications beyond short-term hoarseness. Histopathological examination confirmed the diagnosis of a bronchogenic cyst. During the follow-up period (3 years), there were no complications, the patient did not report any symptoms, and the imaging studies did not indicate any abnormalities.

\section{Discussion}

Bronchogenic cysts are a rare type of mediastinal mass. In approximately $80 \%$ of cases, they are located within the mediastinum; rarely, they are also found in distal pulmonary parenchyma [6]. Mediastinal cysts are usually unilocular, well-demarcated, lined with ciliated columnar epithelium, and filled with mucous content [3, 6-8]. They originate from disturbances in the embryonic evolution of the primitive esophagus and tracheobronchial tree [7]. Mediastinal cysts can cause typical symptoms such as cough, hoarseness, dysphagia, dyspnea, pneumonia, bronchitis, superior vena cava syndrome, arrhythmia, or Horner's syndrome [3, 8]. Less frequently reported complications include rupture and intracystic bleeding, infection of the cystic content, pneumothorax resulting from the rupture of a cyst communicating with the respiratory tract, as well as the extremely rare malignant transformation of the tumor $[3,7]$. The occurrence and severity of the symptoms are related primarily to the location of the tumor and, to a lesser extent, to its size. If the cysts remain asymptomatic, they are sometimes discovered incidentally $[1,3,4]$.

Prenatal testing enables the detection of bronchogenic cysts at about 20 weeks of gestation. Large cysts can cause pressure on the mediastinal organs of the fetus, pulmonary hypoplasia, or cardiac disorders, which in turn may result in generalized edema and fetal death. During the neonatal period, the main risk associated with the presence of cysts is breathing disorders that can lead to acute respiratory failure [7].

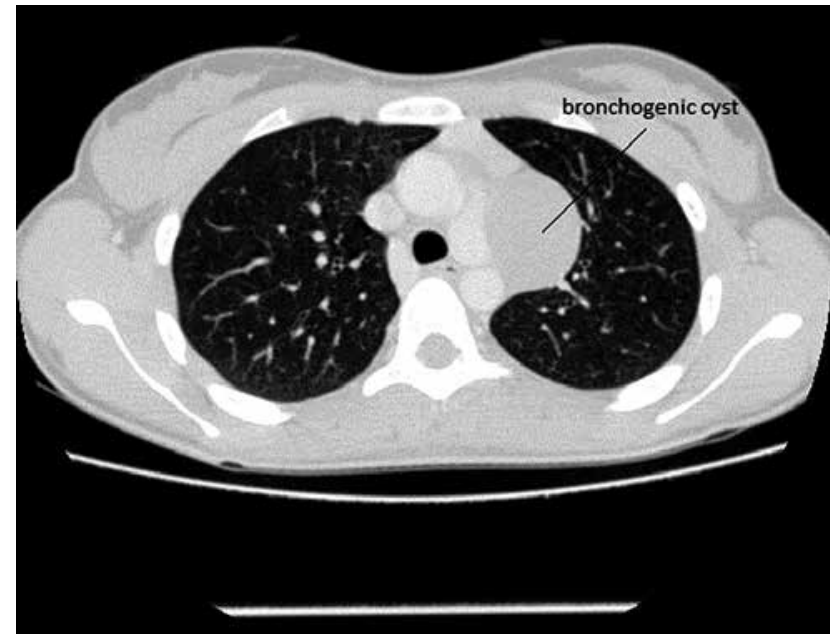

Fig. 1. Computed tomography showing a mediastinal cyst

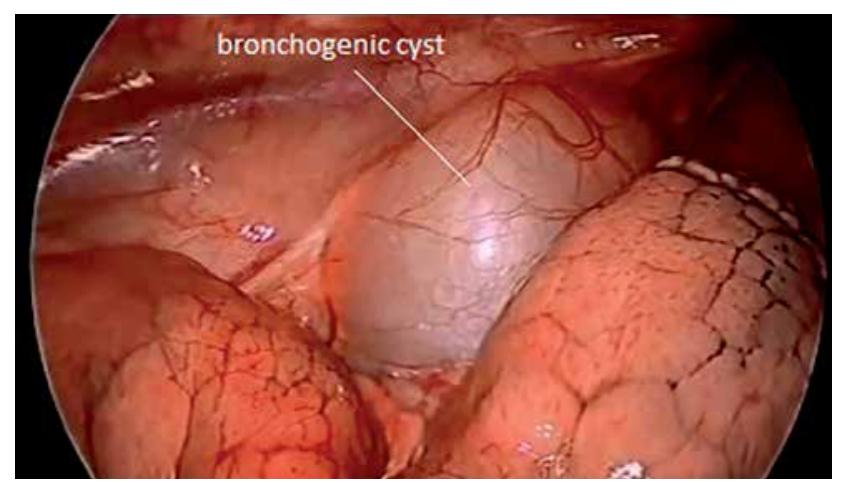

Fig. 2. Intraoperative view of the mediastinal cyst

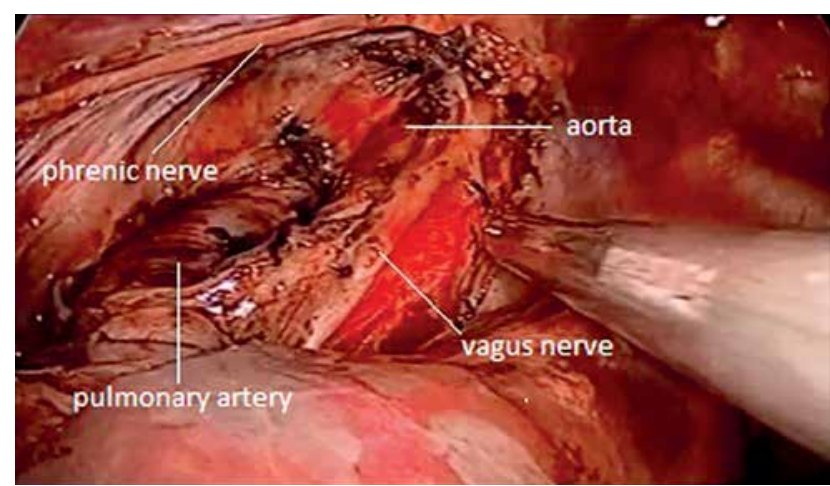

Fig. 3. Intraoperative view - operating field after cyst resection

The majority of mediastinal cystic masses are detected on chest radiographs taken because of the appearance of typical symptoms or, accidentally, in the course of evaluation performed for other reasons. Following the discovery of the tumor on the chest radiograph, the diagnostic process should be supplemented with a CT or MRI scan of the chest, which is not only helpful in reaching the diagnosis and determining the tumor's relation to adjacent organs, but also provides an opportunity to select appropriate treatment methods and strategies [1, 2, 6]. Establishing the precise location of the tumor and its relations to adjacent structures is very important in anticipating potential intra- 
operative difficulties: it facilitates adequate preparation of the patient for surgery and efficient trocar placement $[2,9,10]$. The management of mediastinal cysts is a topic of controversy. Some authors recommend excision only if the cyst is symptomatic, or if malignant conversion is suspected. Others suggest excision in all cases to confirm the histological type of the tumor and to prevent possible complications [1, 2, 3, 6, 8]. Jung et al. suggest early cyst excision immediately after the diagnosis to avoid potential complications and to allow for a more comfortable and easier resection. Delaying the surgery can result in the formation of adhesions to the surrounding tissues and anatomical structures, making the resection more difficult [10].

In our case, the mediastinal cystic mass was diagnosed accidentally during a chest $X$-ray examination performed after the girl suffered chest trauma at the age of 10. Initially, surgical treatment was not applied due to the lack of symptoms. The patient remained under ambulatory monitoring. In subsequent CT examinations, the lesion remained stationary. Due to the emergence of symptoms (chronic cough and hoarseness) at the age of 17 years, we decided to expand the diagnosis with MRI imaging, and the patient was qualified for surgery.

A common procedure in such cases is the total removal of the lesion. Increasingly, the procedure is performed by thoracoscopic technique to avoid extensive thoracotomy and related complications. In many hospitals treating adult patients, the thoracoscopic approach is the primary therapeutic option [2, 8].

Tölg et al. compared the operative outcomes in children undergoing open and thoracoscopic excision of bronchogenic cysts, demonstrating a significant advantage of the thoracoscopic treatment. Compared to thoracotomy, thoracoscopy reduces postoperative drainage, offers the possibility of early patient mobilization and effective physiotherapy, improves patient comfort (less pain, less risk of intercostal muscle damage and rib fractures), reduces the amount of analgesics used, the costs of postoperative treatment, and the length of hospitalization, and achieves better cosmetic effects [9]. The significant advantages of thoracoscopic resection have also been emphasized by other authors $[5,8]$. The operating time, the percentage of early complications, and the rates of reoperation were comparable in both groups [9]. In children and adolescents, the use of thoracoscopic access eliminates the risk of chest and shoulder girdle deformities or curved thoracic spine, which often occur after extensive thoracotomy [4]. Thoracoscopy permits good exposure of the entire thoracic cavity including the mediastinum. It also enables better evaluation of the anatomical relationships between the relevant structures [10]. This increases the comfort and safety of the procedure and reduces the risk of iatrogenic injuries
$[3,5,10]$. The advantages and benefits listed above were also observed in our patient. The properly performed 3D reconstructions of the $C T$ and $M R I$ studies led to the development of operational tactics and the precise placement of trocars. Thoracoscopic access provided excellent visualization of the operative field, enabling the surgeon to perform a precise dissection of the bronchogenic cyst while sparing the anatomically and functionally important structures of the mediastinum - the large vessels, trachea, esophagus, vagus and phrenic nerve, and especially the recurrent laryngeal nerve, which adhered closely to the posterolateral wall of the cyst and was probably the cause of increasing hoarseness. The precision of the dissection was facilitated by the use of the harmonic scalpel.

\section{Conclusions}

It should be noted that, considering the benign nature of this lesion, thoracoscopy as a minimally invasive method (characterized by easier postoperative course, shorter hospital stay, reduced treatment costs, better cosmetic results, and smaller rates of long-term complications) is an excellent alternative to open surgery. In children, thoracoscopy should be the primary method of choice.

\section{Disclosure}

Authors report no conflict of interest.

\section{References}

1. Knudtson J, Grewal H. Thoracoscopic excision of a paraesophageal bronchogenic cyst in a child. JSLS 2004; 8: 179-182.

2. Muramatsu T, Shimamura M, Furuichi M, Takeshita S, Morooka H, Tanaka Y, Yagasaki C, Ohmori K, Shiono M. Thoracoscopic resection of mediastinal bronchogenic cysts in adults. Asian J Surg 2011; 34: 11-14.

3. Barbetakis N, Asteriou C, Kleontas A, Papadoupoulou F, Tsilikas C. Videoassisted thoracoscopic resection of a bronchogenic esophageal cyst. J Minim Access Surg 2011; 7: 249-252.

4. Bratu I, Laberge JM, Flageole H, Bouchard S. Foregut duplications: is there an advantage to thoracoscopic resection? J Pediatr Surg 2005; 40: 138-141.

5. Lau CT, Leung L, Chan IHY, Chung PHY, Lan LCL, Chan KL, Wong KKY, Tam $\mathrm{PKH}$. Thoracoscopic resection of congenital cystic lung lesions is associated with better post-operative outcomes. Pediatr Surg Int 2013; 29: 341-345.

6. Maurin S, Hery G, Bourliere B, Potier A, Guys IM, De Lagausie PD. Bronchogenic cyst: clinical course from antenatal diagnosis to postnatal thoracoscopic resection. J Minim Access Surg 2013; 9: 25-28.

7. Rios LTM, Junior EA, Nardozza LMM, Moron AF, Martins MGl. Prenatal diagnosis and postnatal findings of bronchogenic cyst. Case Rep Pulmonol 2013; 2013: 483864.

8. De Giacomo T, Diso D, Anile M, Venuta F, Rolla M, Ricella C, Coloni GF. Thoracoscopic resection of mediastinal bronchogenic cysts in adults. Eur J Cardiothorac Surg 2009; 36: 357-359.

9. Tölg C, Abelin K, Laudenbach V, de Heaulme O, Dorgeret S, Lipsyc S, Aigrain Y, de Lagausie P. Open vs thorascopic surgical management of bronchogenic cysts. Surg Endosc 2005; 19: 77-80.

10. Jung HS, Kim DK, Lee GD, Sim HJ, Choi SH, Kim HR, Kim YH, Park SI. Video-assisted thoracic surgery for bronchogenic cysts: is this the surgical approach of choice? Interact Cardiovasc Thorac Surg 2014; 19: 824-829. 